\title{
Assumption on Curriculum System Construction of Environmental Design Specialty under the Background of Application Transformation
}

\author{
Tianshun $\mathrm{Hu}$ \\ Huanghe Science \&Technology College \\ Zhengzhou, China
}

\author{
Yunjia Wei \\ Eastern International Art College \\ Zhengzhou, China
}

\begin{abstract}
Nowadays, the national economy is developing rapidly, and the demand of market for talents is changing tremendously as well. After years of development, although environmental design specialty expands continuously, there are quite lot problems in the segment of linkage to the market, as the original curriculum formation can no longer satisfy the development requirement of environmental design specialty under the background of national application transformation. The necessity of reform has been analyzed from various aspects in this paper, and a bold assumption on curriculum system of environmental design specialty has been proposed from the aspect of course arrangement in the four years of college.
\end{abstract}

Keywords-environmental design;

transformation; curriculum system; assumption

application

\section{INTRODUCTION}

Environmental design specialty is a subject with strong professional practicality and applicability, involving extensive fields. From the current curriculum system of environmental design specialty, it can be seen that cultivating talents professionally is mainly to stress the students' practicality and their connection with society, and even they can generate value directly after their graduation. However, the actual implementing effect is not very satisfactory. Reasons for that include the students themselves, and problems also exist in the curriculum system construction for that major.

\section{CAPABILITIES OF ENVIRONMENTAL DESIGN TALENTS NEEDED BY THE SOCIETY}

The core capability of students specialized in environmental design is their design capability, which may influence the final actual molding effect. Drawing ability is students' basic learning contents, and the expression ability of drawing and plan is related to the presentation and communication of designing scheme. Drawing ability is related to professional competence, while expression ability is a reflection of professional competence on one hand, and on the other, it is an expression of communication, the manner of dealing with others and one's behaviors. The two abilities reflect the design capability level and aesthetic level together.

\section{CURRENT SituAtion OF ENVIRONMENTAL DESIGN TEACHING}

Top-level design is to cultivate the students' unique understanding, actual expression skill and actual operation capability in terms of indoor and outdoor environmental design through undergraduate courses. However, precedence relationship exists in the course establishment in terms of courses arrangement in teaching process, and connection is absent among the precedence relationship, making teaching effects and achievements not prominent. There are several reasons for that situation as below:

\section{A. School-running Conditions}

Besides the faculty and facilities, one important point for school-running is regional advantage and the advantage of city location, for instance, in coastal cities and Beijing, Shanghai, Guangzhou as well as capital cities, large-scale exhibitions and activities may hold frequently, which are advantages compared with other second- and third-tier cities. As we all know, environmental design is of strong practicality, which needs students to see more, and to think and obtain enhancement on the basis of that, thus to form their own knowledge. As a result, when conducting such design as jewelry exhibition design, clothing store design and hotel design, it will be quite easy for them to form a design idea quickly. Students cannot see enough examples and are lack of spatial experience, and the teaching of some design courses just stay on the stage of watching the drawings, which have restricted students' ability development.

\section{B. Insufficient Connection between Theory and Practice, \\ Lack of Phased Conclusion and Knowledge Summary}

During the four-year college, students specialized in environmental design will acquire quite a lot knowledge about artistic theory, such as history of Chinese arts and crafts, history of architecture, history of industrial design, modern and contemporary history, Chinese and foreign art history etc.. Yet in the practical application process, those historical theories haven't been connected with practice better. Students just take them as historical knowledge, and haven't improved them to the level of connecting with 
practice. When learning a design at new stage, historical theories haven't been absorbed better, as they just stay on superficial knowledge.

\section{Establish Courses Blindly with Insufficient Cohesion}

Students tend to learn passively in the teaching process. The curriculum teaching system for the four years has been established, yet some of them can be consolidated. For instance, although the contents of Basic Course of Interior Design and Living Space Design of Interior Design are different, the course evaluation contents of interior design basis and living space design are the living space where students live for a long time, and quite a lot of the contents are repeated in the teaching process, therefore, it is necessary to consolidate these courses.

\section{ASSUMPTION ON CURRICULUM SYSTEM REFORM}

Under the background of application transformation, and based on the problems exist in previous teaching process, teaching effect and curriculum system design, a brand new curriculum construction assumption has been put forward taking the four-year college education as an example to improve curriculum system from the perspective of social application.

The design ideas of overall curriculum system for the four-year college education are such four stages as introduction, elucidation, transition and conclusion. "Introduction" refers to specialty foundation and design basis; "elucidation" refers to initial stage of design ability cultivation; "transition" refers to the improving stage of design ability cultivation; "conclusion" refers to the design practical ability cultivation and conclusion stage. These four stages are indispensable, and the necessity stage task shall be accomplished each year as per the division of four years. In addition, the phased assessment shall be conducted to strengthen students' conclusion ability and comprehensive capability, with the specific curriculum system design as follows:

\section{A. "Introduction", Namely Specialty Foundation and Design Basis}

First semester of freshman year: cultivation of specialty basic ability.

Make the students to form good picture composition, color, spatial expression and imagination abilities gradually, and help students to grasp the ability to think and make presentation and expression. Main courses established for this stage are Sketch, Color, Three Composition, The Art of Thought, Speech and Eloquence etc., and proposition design and presentation shall be conducted at the end of this semester. Curriculum design will cultivate students' specialty basic ability on one hand, and on the other, it will help students to develop a design habit of being diligent in thinking, and students' oral speech ability and the ability to accommodate alterations will get exercise. At the initial stage of learning design, thinking and expression are the foundation laid for design specialty from the perspective of thought. Form a good habit, the feeling of being lost won't appear when there are design tasks.

Second semester of freshman year: cultivation of design basis.

The students will be brought into design specialty in this semester to learn about environmental design, grasp the drawing expression of design basis, and master the construction technology, procedure and decorative material in the process of combination of design with practice. Make students recognize the future of this specialty as well as the characteristics and process of the industry they will be engaged in clearly. Main courses established for this stage are Hand Drawing, Computer Aided Design, Interior Design Basis, Decorative Material and Construction Technology, and relevant proposition design and presentation of basic courses shall be conducted at the end of this semester.

\section{B. “Elucidation”, Namely Initial Stage of Design Ability Cultivation}

First semester of sophomore year: cultivation of design ability.

Students may start to learn design in a real sense at this stage, before starting the design class, the students shall be guided with conscious to treat design correctly in order to make them grasp the design methods and achievements of ancient environmental design, and be able to design a smallscale architecture space. Main course established for this stage are History of Design, Design Methodology, Smallscale Architecture Space Design and the proposition design and presentation at the end of this semester.

Second semester of sophomore year: cultivation of design ability.

Students' knowledge level shall be broadened further with strong logicality for thinking about problems and more perfect integration concept. The learning of commercial space design, as well as the cognition of design and popular culture trend will mainly be conducted at this stage. Main course established for this stage are Commercial Space Design, Design and Popular Culture Trend, Proposition Design and Presentation etc..

\section{C. “Transition” Namely The Improving Stage of Design Ability Cultivation}

The improving state of design ability pays attention to the ability of students to combine design with practice, and strengthen students' experience and appreciation on space, as well as find out differences in combination with sample questions and design companies to eliminate them one by one, thus to attain the effect of design ability enhancement. Main course established for this stage are Design Survey, sample questions Design, Design Conclusion and proposition design and presentation at the end of this semester. Among which, sample questions refers to design and transform the existing design items, to cultivate students' ability of finding out and resolving problems; the course of Design Conclusion is different from previous design courses, students' problems are different form one another, yet they 
can be divided into the following aspects: design ability, construction technology, material and expression ability. In accordance with students' insufficiency revealed at the time of sample questions design, through the study of this course, the conclusion on commonly-used construction technology can be conducted if students are unfamiliar with construction technology; conclusion on material can be conducted if students are unfamiliar with materials; software capability can be strengthened appropriately if students are unsatisfied with design expression and picture effect; students' divergent thinking ability can be cultivated if they haven't developed a design idea.

\section{D. "Conclusion" Namely the Cultivation and Conclusion Stage of Design and Practice Ability}

The forth year is the stage for students to conduct specialty practice, which pays attention to the cultivation and conclusion of students' design and practice ability. Make the students to enter into companies and learn from specialty practice, to know well about the procedure of design and commercial operation, to conduct bidding for actual projects or to practice in relevant direction of the specialty, such as engineering supervision, engineering construction, and furniture design and so on. The first semester of this stage is mainly for practice learning, and practice conclusion and defense shall be conducted at the end of this semester to present design achievement of this period; the second semester is mainly for graduation creation, which apply the knowledge acquired in the four years to design, and make public design defense to control quality strictly.

\section{CONSTRUCTION OF A NEW CURRICULUM SYSTEM IN ORDER to CUltivate THE ABILITIES OF STUDENTS}

\section{A. Cultivation of Students' Design Ability}

1)Establish Design Method Course. Design ability is one of the essential abilities of students specialized in environmental design. However, most colleges fail to teach design method in class, instead of that, they establish such courses as Living Space Design, Commercial Space Design, and Residential Landscape Design without clear aim. In addition, when teaching each space design, the problem and standard needed to pay attention to haven't been improved to the level of design method, making most of the students at a loss. Therefore, it is necessary to establish the course of design methodology.

2)Strengthen the Cultivation of Aesthetic Ability. The students first entered into college are free from their parents' control just like a runaway horse, and although their view of world, life and value has been shaped, they are lack of more clear cognition of beauty. The contents of beauty are extremely extensive and diversified; therefore, each student's interests shall be valued in terms of cultivation of design aesthetic ability, and read extensively of multi-culture to enhance aesthetic ability.

3)Strengthen the Cultivation of Reading Ability. Reading is not just refer to read books, it also refer to watching TV and film, or to experience on-site. For example, if we want to design a coffee house and we have never drunk coffee or entered a coffee house without any experience of this, then how can we design? We will do nothing but to search relevant data and pictures of coffee house through internet. How can such a design be recognized? As a result, on-site design is also very important for learning design, as we shall not just talk it on paper.

4) Strengthen the Cultivation of Thinking Ability. It is an essential condition to make everything a success to see more, diligent in thinking and put them into action, especially for the students specialized in environmental design. Design is the action to settle a series of difficult problems after thinking. So thinking is quite important and the students' thinking ability shall be cultivated with conscious. Think without any restrain, and connect some uncorrelated things to exercise spatial thinking ability and the active level of thinking.

\section{B. Cultivation of Students'Drawing Ability}

Drawing ability is an important way for designers to express their design ideas. No matter a design is good or bad, it shall be expressed though drawing. Students shall be not only required to know drawing standard, such as tagging method, line width rule, understand various symbols in design drawing, but also required to master the knowledge in terms of construction technology, understand the drawing relevant to specialties of water, electricity and heating. Otherwise, the drawing generated cannot cooperate with the construction of water, electricity and heating. In addition, drawing level just stays on initial stage of plan or vertical plan, and the design ability will be influenced as well.

1)Strengthen Mastering of Construction Technology. Construction technology is the essential knowledge for drawing. In the process of learning, students shall be organized to visit construction site, to learn the performance and dimensions of various material, only grasp these knowledge, can they draw the sectional drawing, constructional detail and other drawings correctly.

2)Strengthen Learning of Computer Aided Design Software. Software is just used for design expression to reflect a more perfect design. Yet the ability of drawing is not the ability of design which is a misunderstanding of many beginners. Generally, the college will establish the computer aided design course for about one month, and the contents taught are basic operations. More time shall be spent on exercise after class and learning habit with selfconscious shall be formed to express a more perfect design.

In addition, when certain foundation has been obtained, intensive training shall be adopted. Personnel from special design expression agency shall be invited to serve as teachers or the design expression agency may be delegated directly to conduct intensive training to enhance design expression ability. 


\section{Expression Ability}

Expression ability can be divided into self-marketing expression and design scheme expression which are indispensible.

1)Self-marketing expression. First of all is the transmission of personal image. Just imagine what impression will a slovenly designer give to the client?

2)Design scheme expression. Whether a design scheme is good or bad depends on design on one hand, and the oral expression on the other. Students have been in a position of being taught for a long time without actual initiative, and the oral expression ability is quite weak. Therefore, the course of Speech and Eloquence can be established in the process of teaching. Each course shall adopt the form of answering questions and scoring, and receive evaluation from all of the students and teachers, thus to exercise students' expression ability and the ability to accommodate alterations.

\section{CONCLUSION}

Previous curriculum design is lack of cohesion, integration and phased conclusion on curriculum design system with unsatisfactory teaching effect. However, in the four years of college, different tasks shall be finished each academic year, and at the end of each semester, a course of "proposition design and presentation" which is like final examination is specially designed, playing a role of conclusion on and thinking about this semester's courses. And the students are required to make scheme presentation one by one, thus students' oral expression ability, scheme picture expression ability as well as relevant knowledge will be enhanced through continuous conclusion and accumulation. Through curriculum system reform to cultivate students' the above three abilities with conscious, a new look will absolutely be brought to environmental design teaching.

\section{REFERENCES}

[1] Wang Dakai, Reflection on Teaching Reform of Environmental Art Design Specialty in Colleges [J].Teaching Forum.2006.

[2] Zheng Junde, Development Trend of Environmental Art Design Specialty in Colleges [J].Zhejing Arts \& Crafts.2012. 